\title{
Successive reversals of a position response in isopods '
}

\author{
MARION D. HARLESS \\ CENTRAL WASHINGTON STATE COLLEGE
}

In a Y maze isopods, Porcellio scaber, learned a position discrimination and six reversals; a light was presented following incorrect responses. There was no significant decrease in the number of errors or trials to criterion over the seven discriminations.

Thompson (1957), using a correction technique and both positive reinforcement and punishment, found position discrimination in the isopod, Armadillidium vulgare, although there was no statistical evidence of learning set formation over successive reversals. The present study investigated successive reversals of a position discrimination in isopods (sowbugs) using a noncorrection technique and punishment.

\section{Method}

Ss were five large female isopods, Porcellio scaber, gathered at Pullman, Wash. Ss were maintained in individual jars with carrot, lettuce, paper toweling, and a vial of water.

The maze was a $4-3 / 4$ in. $Y$ shaped piece of glass connecting tubing with openings $5 / 16$ in. in diameter. One arm of the maze was nearly $1 / 4$ in. longer than the other; to prevent the possibility of distance traveled being utilized as a cue, the position of the long arm was randomized across Ss and across trials. The glass tubing was held by two rubber bands on a $6-1 / 2 \times 3-1 / 8$ in. block of wood. Two depressions at one end of the wooden platform each held a small glass bottle which served as a goal box. The use of glassware precluded the opportunity for $\mathrm{Ss}$ to climb and to stop at corners, celling-wall angles, etc. Behind the bottles was a small plece of sheet metal which presented a homogenous field towards which Ss traveled. Pivoting metal doors were placed at the three maze openings. With the exception of the glassware, all parts of the apparatus were painted with white enamel. A goose neck lamp was positioned with the lower surface of a $100 \mathrm{~W}$ bulb 5-1/2 in. above the end bottles. An electrical timer was used in recording running speeds.

Each $S$ was given 10 massed preference trials in the mare. On the basis of response tendency each $\mathrm{S}$ was asgigned to the nonpreferred position on the first discrimination problem.

Testing was conducted as follows: S was remored From the home jar, placed in the entrance of the maze, and the timer started. A constriction $5 / 16$ in. from the entrance demarcated the start box; if $S$ did not move out of this area within $10 \mathrm{sec}$ it was touched with a pipe cleaner to initiate movement down the maze. The prodding technique was called for only oc- casionally. When $S$ entered an end bottle, E closed the door immediately and turned off the timer. If the response was correct the animal was returned to the home jar. If the response was incorrect the light was turned on simultaneously with door closure; S was detained in the end bottle for $60 \mathrm{sec}$ and then removed to the home jar until the next trial. Trials were separated by the time necessary to run the other four Ss and to cool the maze between trials. Heat generated by the light bulb necessitated the cooling period when incorrect responses were made, and to equate for the dispersion of possible odors the interval was observed on all trials. Trials were run in blocks of five with at least $1 \mathrm{~h}$ between blocks when two blocks were given on one day. All testing was conducted during evening hours in a small room with overhead illumination.

Criterion was set at eight correct responses out of ten. When S reached criterion, testing was discontinued until the following day, when the first reversal was initiated. The same procedure was continued until six reversals were completed.

Results

As indicated in Table 1, there is no systematic improvement over successive reversals. A Friedman two way analysis of variance of both errors to criterion and trials to criterion yielded no significant differences in performance over the six reversals. Of the 30 total reversals, however, 10 were learned with zero to five errors. A $t$ test for correlated measures indicated no significant difference between running time on the first 10 test trials and the last 10 trials.

Discussion

Since crustaceans respond to a great extent on a tactual basis (Carthy, 1958), it is perhaps unfair on the part of the $E$ to expect isopods to learn a position discrimination in the absence of any observable aids beyond kinesthetic cues. The five isopods did, however, complete seven position discriminations. An animal not being used in the present study was placed in an

Table 1

Errors (total trials) to $8 / 10$ criterion, position discrimination

\begin{tabular}{rrrrrrrr}
\hline$S$ & \multicolumn{7}{c}{ Reversals } \\
& \multicolumn{1}{c}{0} & 1 & 2 & 3 & 4 & 5 & 6 \\
1 & $7(20)$ & $6(18)$ & $16(36)$ & $60(125)$ & $3(11)$ & $19(36)$ & $20(45)$ \\
2 & $113(157)$ & $5(15)$ & $9(20)$ & $6(17)$ & $10(19)$ & $8(22)$ & $15(30)$ \\
3 & $0(8)$ & $73(97)$ & $1(9)$ & $10(24)$ & $16(38)$ & $3(12)$ & $73(124)$ \\
4 & $9(26)$ & $21(42)$ & $0(8)$ & $13(26)$ & $2(10)$ & $39(82)$ & $2(10)$ \\
5 & $9(19)$ & $31(57)$ & $42(75)$ & $2(10)$ & $9(21)$ & $2(10)$ & $4(14)$ \\
\hline
\end{tabular}


end bottle; the light was turned on and $302 \mathrm{sec}$ later the isopod was dead. The death, along with the data presented herein, indicate that the light, together with the heat produced and the subsequent dessicating effect, served as an aversive stimulus to the isopods. Dinsmoor (1960) in reviewing studies of abnormal behavior in animals discusses extreme vacillation and hyperactivity as behaviors which follow prolonged punishment. Vacillation at the choice point persisted for 26 min on one trial of the present study. Except for S 2, all animals exhibited increasing amounts of vacillation with progression through the reversals. Although the additional minutes spent at the choice point lengthened the running speed, some trials were characterized by extremely rapid speeds $(3 \mathrm{sec}$ ) and mean running speed over reversals did not increase. These short trials ended in continued random hyperactivity in the goal bottle and two of the animals (1 and 3 ) seemed to become especially "frantic" on the sixth reversal. Additional reversals would probably have required an even greater number of trials, and it is doubtful that Ss 1 and 3 would have survived another reversal. It must be remembered that punishment alone was used in the present research. Traditional reversal learning research and learning set experiments use positive reinforcement, occasionally in combination with punishment. An experiment utilizing only positive rein- forcement might yield reversal data for isopods which are more similar to those for lower vertebrates (Warren, 1965). The isopods of the present study performed slightly better in terms of mean errors to criterion over six reversals than did octopus (Mackintosh \& Mackintosh, 1964) which recelved food as reinforcement. Even though isopods do not seem to form learning sets, it is quite significant that a crustacean is able to learn successive reversals with punishment alone.

\section{References}

CARTHY, J. D. An introduction to the behavior of invertebrates. New York: Macmillan, 1958.

DINSMOOR, J. A. Abnormal behavior in animals. In R. H. Waters, D. A. Rethlingshafer, \& W. E. Caldwell (Eds.), Principles of comparative Psychology. New York: McGraw-Hill, 1960. Pp. 289-324.

MACKINTOSH, N. J., \& MACKINTOSH, J. Performance of Octopus over a series of reversals of a simultaneous discrimination. Anim. Behav., 1964, 12, 321-324.

THOMPSON, R. Successive reversals of position habit in an invertebrate. Science, 1957, 126, 163-164.

WARREN, J. P. Primate learning in comparative perspective. In A. M. Schrier, H. F. Harlow, \& F. Stollnitz (Eds.), Behavior of nonhuman primates. Vol. 1. New York: Academic Press, 1965. Pp. 249-281. Note

1. This research was completed while the writer was at Washington State University, Pullman, Washington. Part of the paper was read at Washington State Psychological Association Convention in Rosario, Washington, May, 1963. 